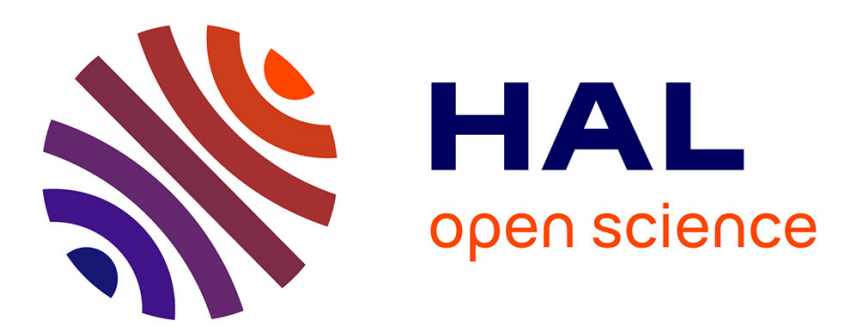

\title{
Differential rotation between lithosphere and mantle: a consequence of lateral mantle viscosity variations
}

\author{
Y. Ricard, C. Doglioni, R. Sabadini
}

\section{To cite this version:}

Y. Ricard, C. Doglioni, R. Sabadini. Differential rotation between lithosphere and mantle: a consequence of lateral mantle viscosity variations. Journal of Geophysical Research, 1991, 96 (B5), pp.8407-8415. 10.1029/91JB00204 . hal-02046601

\section{HAL Id: hal-02046601 \\ https://hal.science/hal-02046601}

Submitted on 2 Feb 2021

HAL is a multi-disciplinary open access archive for the deposit and dissemination of scientific research documents, whether they are published or not. The documents may come from teaching and research institutions in France or abroad, or from public or private research centers.
L'archive ouverte pluridisciplinaire $\mathbf{H A L}$, est destinée au dépôt et à la diffusion de documents scientifiques de niveau recherche, publiés ou non, émanant des établissements d'enseignement et de recherche français ou étrangers, des laboratoires publics ou privés. 


\title{
Differential Rotation Between Lithosphere and Mantle: A Consequence of Lateral Mantle Viscosity Variations
}

\author{
YANICK RICARD ${ }^{1}$ \\ Dipartimento di Fisica, Settore Geofisica, Universitì di Bologna, Italy \\ Carlo DOGLIONI \\ Dipartimento di Scienze Geologiche, Università di Ferrara, Italy \\ ROBERTO SABADINI ${ }^{2}$ \\ Dipartimento di Fisica, Settore Geofisica, Universita di Bologna, Italy
}

\begin{abstract}
The description of plate motions in the so-called hotspot reference frame introduces a global rotation of the lithosphere with respect to the mantle. This rotation, called toroidal field of degree 1 , is roughly westward. It reaches an amplitude of about $2 \mathrm{~cm} / \mathrm{yr}$ and has been consistently found in the different generation of plate tectonic models. Various authors have tried to relate this observation to the deceleration of the Earth's rotation, to polar wander, or to tidal drag. However, these different physical mechanisms cannot explain the requested amplitude. In this paper, we compare the values of this rotation vector using different relative plate motion models expressed in the hotspot reference frame. In a model Earth with lateral viscosity variations, a differential rotation is predicted. The observed net lithospheric rotation is consistent with the dynamics of a model Earth where the asthenospheric viscosity below the oceans is at least one order of magnitude lower than underneath the continents. This relative westward drift of the lithosphere may account for the significant structural differences between east or west dipping subduction zones.
\end{abstract}

\section{The Differential Rotation Between LITHOSPHERE AND MANTLE}

The motions between plates are computed from three independent data sets. The first consists in the spreading rates on ridges deduced from the Earth's magnetic inversions recorded in the frozen mid-oceanic basalt. The second set includes the strikes of the transform faults which are assumed to be parallel to the relative motions. Finally, the earthquakes slip motions help to constraint the motions particularly at shear or converging boundaries. From these data, only relative motions can be deduced. The choice of an origin in the angular velocity space specifies an absolute reference frame. Of course, the most natural frame would be the one in which the deep mantle has no rotation. Different criteria have been proposed to define practically such a frame. Le Pichon [1968] implicitly suggests that the Antarctic plate remains fixed. Following Burke and Wilson [1972], it is the African plate that could be stationary with respect to the underlying mantle. The most widely accepted reference frame is the one in which the hotspots remain fixed [Wilson, 1965; Morgan, 1971]. These three hypotheses, although conceptually different, lead to the same conclusion: the lithosphere has a west trending average rota ${ }^{\perp}$ ion.

Quantitatively, this lithospheric rotation $\Omega_{L} \mathrm{c}$ n be computed from the surface plate velocity $V^{L}$ by the following

\footnotetext{
${ }^{1}$ Now at Département de Géologie, Ecole Normale Supérieure, Paris, France.

${ }^{2}$ Also at Istituto di Mineralogia, Università di Ferrara, Ferrara, Italy.

Copyright 1991 by the American Geophysical Union.

Paper number 91JB00204.

0148-0227/91/91JB-00204\$05.00
}

equation:

$$
\Omega_{L}=-\frac{3}{2 S_{0}} \int V^{L} \times v d S,
$$

where $u_{r}$ is the unit radial vector and $S_{0}$ is the Earth's surface. This net rotation can also be deduced from the expansion of surface velocities in vector spherical harmonics. The rotation is simply proportional to the toroidal coefficients of degree 1.

Minster et al. [1974] have computed the lithospheric rotation of their AM1 model. It amounts to $0.11^{\circ} / \mathrm{m}$.y. around a pole situated at $129^{\circ} \mathrm{E}$ and $74^{\circ} \mathrm{S}$. This corresponds to a maximum velocity of $1.2 \mathrm{~cm} / \mathrm{yr}$. We compute this average rotation for the model AM1-2 [Minster and Jordan, 1978] expressed in the hotspot reference frame. In that case, the lithospheric rotation reaches $0.26^{\circ} / \mathrm{m} . \mathrm{y} .(2.8 \mathrm{~cm} / \mathrm{yr})$ around $66^{\circ} \mathrm{E}$ and $54^{\circ} \mathrm{S}$. We also used the HS2-NUVEL1 model [DeMets et al., 1990; Gripp and Gordon, 1990]. Following their results, the net lithospheric rotation should be of $0.32^{\circ} / \mathrm{m} . y$. $(3.6 \mathrm{~cm} / \mathrm{yr})$ around $64^{\circ} \mathrm{E}$ and $52^{\circ} \mathrm{S}$.

The last two models (AM1-2 and HS2-NUVEL1) have been computed using different relative motion models but fitting the same propagation rates of five volcanoes and the same trends of nine chains. The difference in their lithospheric rotations is thus only related to the difference in the relative velocity models. The selected hotspots were only located on, or very close to, the Pacific plate. On the contrary, the AM1 model was constructed using 20 hotspot tracks sited on eight different plates. However, for the slow moving plates, the actual azimuth of the hotspot chains cannot be precisely observed.

To be sure that our estimation of the net lithospheric rotation is not strongly biased by the weight of the Pacific area nor unrealistically influenced by the selection of imprecise traces, we perform another inversion. We only select traces 
sampling different plates where the absolute velocity is a priori known to be of order or larger than $1.5 \mathrm{~cm} / \mathrm{yr}$. The traces are all taken from the data that entered in the construction of the AM1 model. There are also consistent with the observations of Morgan [1972]. The inversion is performed with the 14 hotspots listed in Table 1. As Minster and Jordan [1978], we use both observed velocities (five data), and observed azimuths (14 data). The first nine traces were used for the determination of AM1-2 and HS2-NUVEL1; we add five more to ensure a better geographical coverage. We chose NUVEL-1 for relative plate motion model and we only readjust the global rotation to match our selected data. Our inversion indicates that the lithosphere has a net rotation of $0.15^{\circ} / \mathrm{m} . \mathrm{y} .(1.7 \mathrm{~cm} / \mathrm{yr})$ around a pole situated at $84^{\circ} \mathrm{E}$ and $56^{\circ} \mathrm{S}$. In columns 6 and 7 of Table 1 , we show the velocity and azimuth of the chosen hotspot traces according to our model. All the computed values but two (Marquesas and Galapagos on the Nazca plate) lie within the prescribed uncertainties. Figure 1 shows the localization of our hotspots on top of a map depicting the tectonic plates taken into account by NUVEL-1. The hotspot velocities deduced from our inversion are also plotted with the observed directions and a priori uncertainties.

Garfunkel et al. [1986] have suggested that the discrepancy between the hotspot reference frame and the no-net rotation frame is a bias due to an overestimate of the migration rates for the Pacific volcanoes. However, the AM1 model was constructed by only fitting the trends of hotspots without taking into account their absolute velocities. Similarly, we also performed an inversion only using the azimuths of our selected hotspots. A global rotation was still found with a rotation pole consistantly located in the southern part of the Indian Ocean but with the smaller amplitude of $1.0 \mathrm{~cm} / \mathrm{yr}$.

Although different, the estimations of the net lithospheric rotation agree with a roughly westward rotation with a pole located in the southern part of the Indian Ocean and an observed velocity of a few centimeters per year. The Pacific hotspots seem to have a relative velocity with respect to the other hotspots which explains the discrepancy between the models. However, it should be clear that this exercise cannot be a test of the hypothesis of hotspots fixity. The relative plate motion models are only valid for the present time and the very last million years, whereas the hotspots fixity applied for a much longer time.

Figure 2 shows the pole, labelled a, of the net lithospheric rotation deduced from our inversion. This rotation is clearly related to the total motion of the Pacific plate. The three poles labelled b, c, and d corresponding to models AM1, AM1-2, and HS2-NUVEL1 are also plotted with a circle whose size is proportional to the amplitude of the motion. The solid circle will correspond to the result of a model and will be discussed later. Due to map distortion at high latitudes, the different poles look rather distant, but their angular distance is at most $30^{\circ}$.

On the basis of geological observations, various authors have also advocated for this differential rotation [Nelson and Temple, 1972; Uyedo and Kanamori, 1979; Doglioni 1990]. Two types of thrust belts have to be distinguished, whether they are related to west or east dipping subductions, that is, whether they contrast or follow the relative eastward rotation of the mantle. The main differences are summarized in Figure 3. Of course, these two types of thrust belts should be considered two end-members; oblique and lateral subductions must be further distinguished in between.

West dipping subductions have a steep inclination of the slab and are associated to back arc basins (e.g., West Pacific, Barbados, Sandwich, Apennines, Carpathians). Thrust belts related to this kind of subduction (contrasting the mantle flow) show low structural and morphologic reliefs, shallow upper crust rocks, very consistent foredeep generated by the roll-back of the subduction hinge, and coeval back arc extension which is eastward propagating and eating the accretionary wedge. The area of active compression is very narrow, usually a few tens of kilometers. In these west dipping subductions, the base plate detachment is never connected to the surface but rather folded and subducted. West dipping subductions are also characterized by arcs with their major convexity oriented toward the east, suggesting to be obstacles to the westward flow of the lithosphere.

East dipping slabs have a shallow dip and are not associated to back arc extensional basins (e.g., American Cordillera, Western Alps, Dinarides, Zagros). Thrust belts related to this kind of subduction (following the mantle flow)

TABLE 1. Hotspot data used to compute the Absolute Motion Model

\begin{tabular}{|c|c|c|c|c|c|c|c|}
\hline Name & Plate & $\begin{array}{c}\text { Longitude } \\
{ }_{\mathrm{E}}\end{array}$ & $\underset{{ }^{\circ} \mathrm{N}}{\text { Latude }}$ & $\begin{array}{l}\text { Observed } \\
\text { Velocity, } \\
\mathrm{cm} / \mathbf{y r}\end{array}$ & $\begin{array}{c}\text { Observed } \\
\text { Azimuth, } \\
\mathrm{N}^{\circ} \mathrm{E}\end{array}$ & $\begin{array}{l}\text { Computed } \\
\text { Velocity, } \\
\mathbf{c m} / \mathbf{y r}\end{array}$ & $\begin{array}{l}\text { Computed } \\
\text { Azimuth, } \\
\mathrm{N}^{\circ} \mathrm{E}\end{array}$ \\
\hline Hawai & Pacific & -155 & 20 & $10.0 \pm 2$ & $-64 \pm 10$ & 8.4 & -59 \\
\hline Marquesas & Pacific & -138 & -11 & $9.8 \pm 2$ & $-45 \pm 15$ & 9.2 & -65 \\
\hline Tahiti & Pacific & -148 & -18 & $11.0 \pm 2$ & $-65 \pm 15$ & 9.1 & -63 \\
\hline MacDonald & Pacific & -140 & -29 & $10.5 \pm 2$ & $-55 \pm 15$ & 8.9 & -64 \\
\hline Pitcairn & Pacific & -130 & -25 & $11.0 \pm 2$ & $-65 \pm 15$ & 9.1 & -67 \\
\hline Juan de Fuca & Pacific & -130 & 46 & & $-54 \pm 15$ & 5.0 & -46 \\
\hline Galapagos & Coco & -92 & -1 & & $45 \pm 10$ & 8.8 & 43 \\
\hline Galapagos & Nazca & -92 & -1 & & $95 \pm 10$ & 5.1 & 81 \\
\hline Yellowstone & N.America & -110 & 45 & & $-120 \pm 20$ & 2.0 & -101 \\
\hline Iceland & N.America & -17 & 65 & & $-43 \pm 30$ & 1.7 & -45 \\
\hline Tristan Da Cunha & S.America & -11 & -37 & & $-73 \pm 30$ & 1.9 & -87 \\
\hline Tristan Da Cunha & Africa & -11 & -38 & & $47 \pm 20$ & 1.7 & 60 \\
\hline Reunion & Africa & 56 & -21 & & $45 \pm 10$ & 1.4 & 40 \\
\hline Ascension & Africa & -14 & -8 & & $55 \pm 10$ & 1.5 & 58 \\
\hline
\end{tabular}

The observed azimuths and rates with their uncertainties are shown in comparison with the predictions deduced from our inversion. 


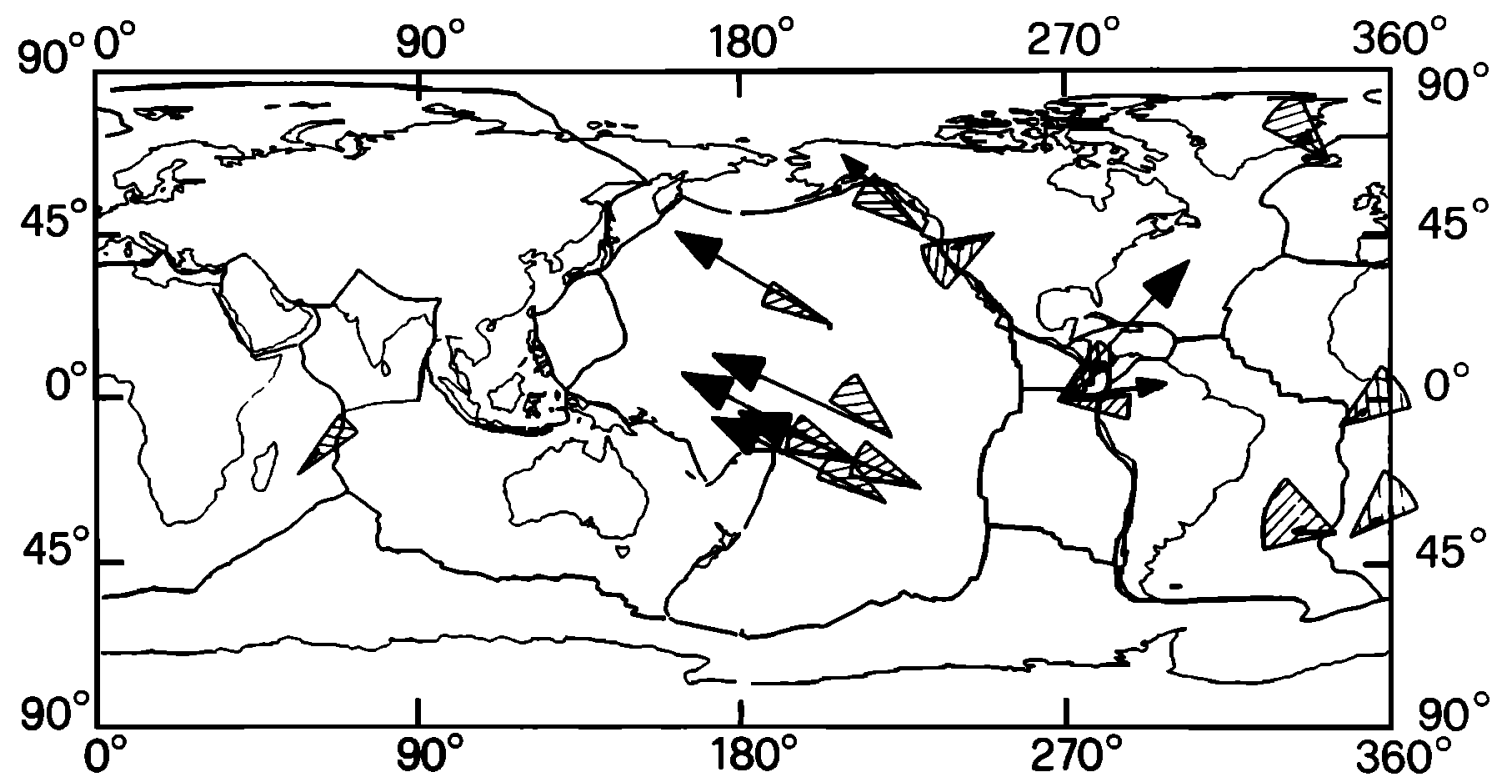

Fig. 1. Selected hotspots used in our computation of the global lithospheric rotation. The azimuth of the observed trends with their estimated uncertainties are also plotted. The arrows correspond to the velocities deduced from the NUVEL-1 model. Their amplitudes are listed in Table 1.

show huge exposures of basement rocks, high structural and morphologic reliefs in contrast to limited and usually shallow foredeep. The Himalayan chain belongs geologically to the same group, although it would appear as parallel to the global rotation depicted in Figure 2.

The two kinds of subductions provide different metamorphic paths for the relative thrust belts. Only in the east dipping thrust belt, coesite-pyrope bearing assemblages and eclogites have been found [Chopin, 1984; Wang et al., 1989], indicating that confining pressures between 20 and $30 \mathrm{kbar}$ are reached. The position with respect to the eastward mantle flow of the decollement plane between the subducted and the overthrusting lithosphere can account for this observation (Figure 3). In the east dipping subductions the basal detachment can bring to the surface deeply buried materials. On the contrary, the metamorphosed rocks sink into the mantle under West-dipping subductions.

Oceanic ridges, continental rift zones, and subduction trenches are generally perpendicular to the differential velocity field depicted in Figure 2. The main deviations from this rule are only found in the North Atlantic ridge, the western portion of the southwest Indian ridge, and the Philippine subduction arc. On the contrary, the major shear zones appear to be parallel to the observed differential velocity.

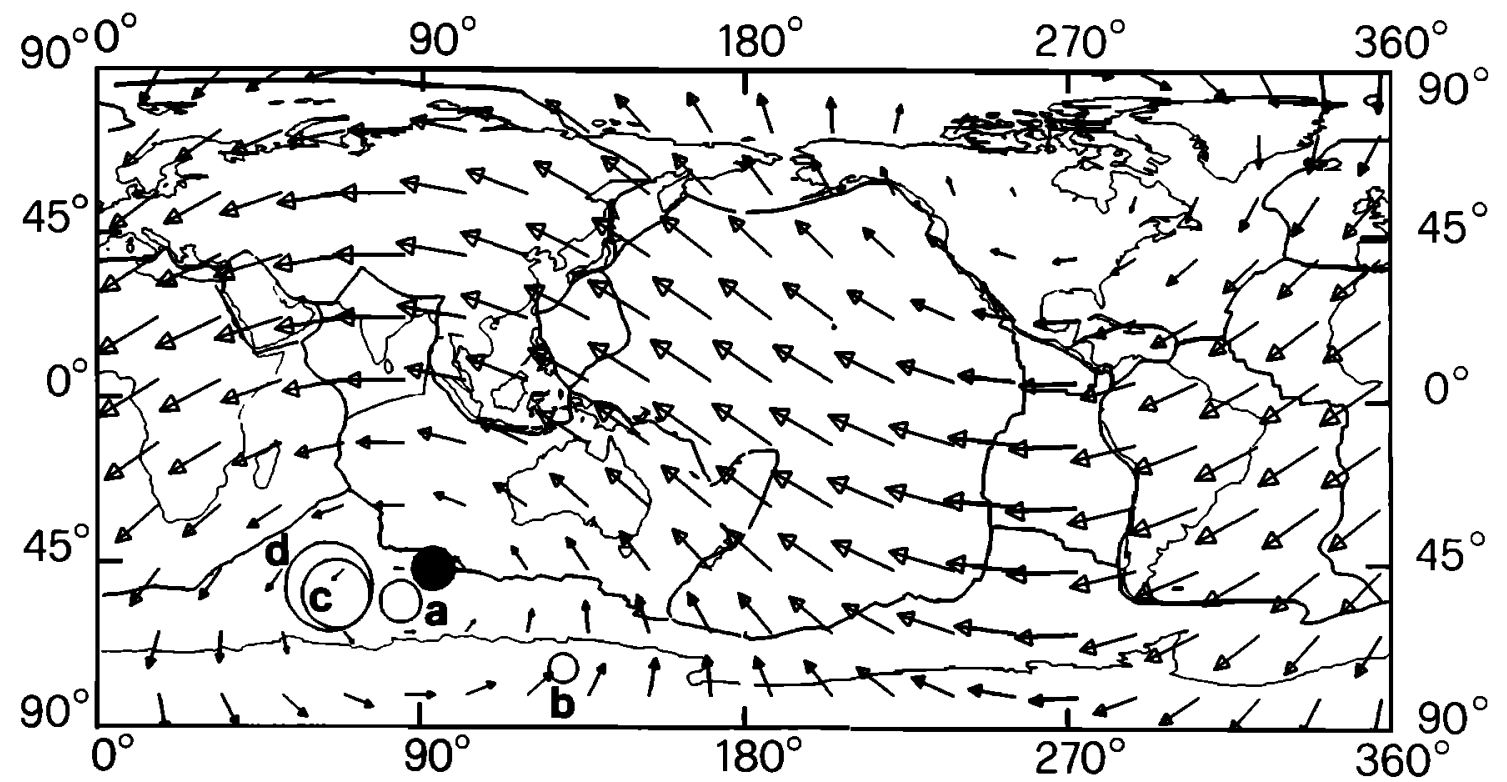

Fig. 2. Net rotation of the lithosphere with respect to the deep mantle. The rotation pole has been deduced from the observations of 14 hotspot traces using the relative motion model NUVEL-1 (a). The maximum velocity reaches $1.7 \mathrm{~cm} / \mathrm{yr}$. We also show the lithospheric rotation poles of the different models AM1 (b), AM1-2 (c), and HS2-NUVEL1 (d) with a circle with size proportional to the predicted rotation amplitude. The solid circle shows the prediction of a model with will be discuss later. 


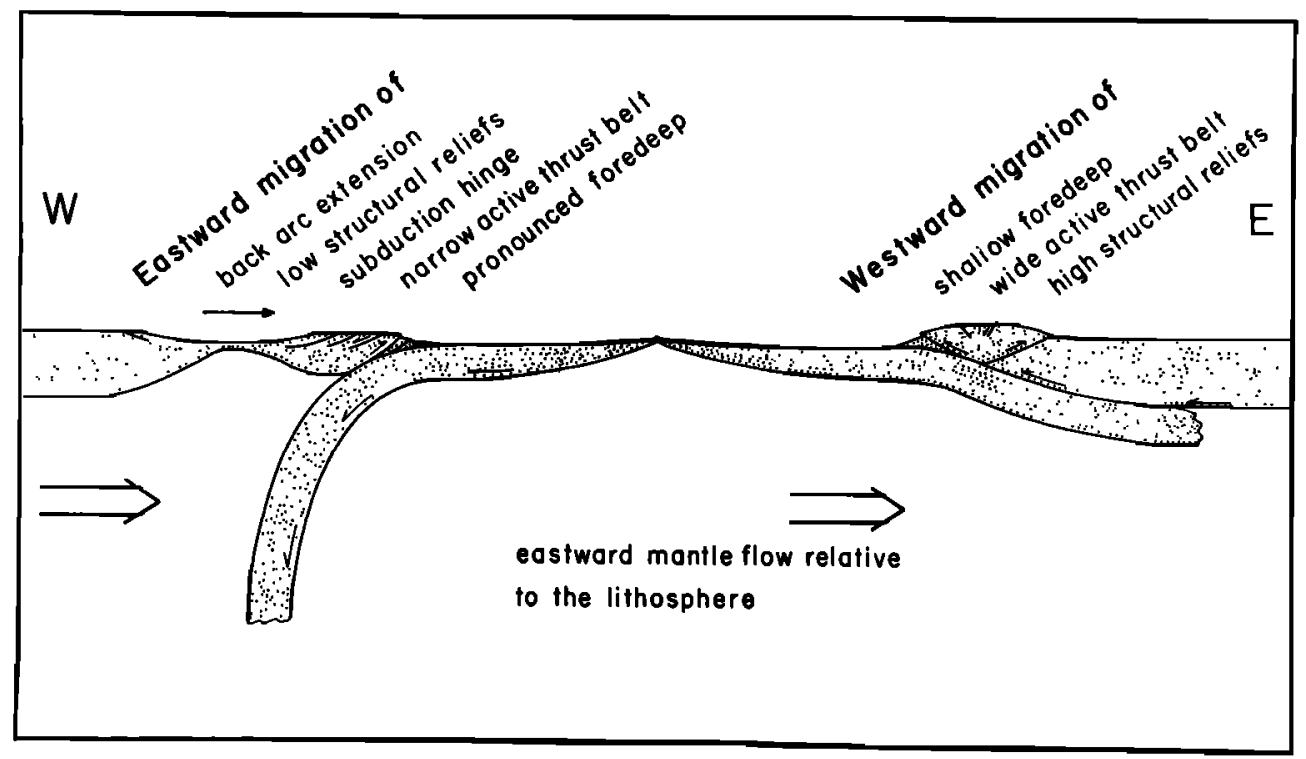

Fig. 3. Comparative sketch between the west and east dipping subductions connected to the relative east ward mantle motion. In the west dipping subduction case, the slab acts as an obstacle to the eastward mantle flow and back arc extension develops due to the lithospheric loss. This will produce an east ward migration of the tectonic setting and a pronounced foredeep. The base plate detachment is in this case folded and subducted. East dipping subduction has a shallow dip. The basal detachment of the eastern plate is reaching the surface; this provides a mechanism to bring deep crustal levels of the thrusting plate at the surface. The subduction hinge is in this case westward retreating. The morphological relief of the thrust belt related to the east dipping subduction is much more developed with respect to the east dipping case.

\section{FaILURE of Radially Stratified Earth Models}

The observation of this differential velocity leads to an old and puzzling problem. Mechanically, in a radially stratified Earth, the canonical reference frame should be the one in which the lithosphere has no-net rotation [Lliboutry, 1974]. In effect, the Navier-Stokes equations applied to a mantle where the viscosity variations are only radial indicate that the toroidal velocity field of degree 1 (global rotation) is uniform through the mantle [Hager and $O^{\prime}$ Connell, 1981]. This means that the toroidal stress field of degree 1 is zero as a consequence of free slip boundary conditions which prevail at the Earth surface.

The possibility of inducing a westward drift by tidal drag has been suggested [Bostrom, 1971; Knopoff and Leeds, 1972; Moore, 1973]. However, Jordan [1974] has clearly shown that tidal drag is far from being significant and that this mechanism should be abandoned. Furthermore, we saw that the observed global rotation has a pole differing significantly to the Earth's pole of rotation. A change in the Earth's rotation pole (true polar wander) would induce a poloidal field related to the readjustment of the equatorial bulge [Sabadini et al., 1990]. It is also responsible for a global rotation of the geography with respect to the inertial reference frame, but it does not produce any significant differential rotation between the lithosphere and the mantle.

Any other possible explanation of lithospheric rotation invoking the application of a net torque will fail because it would change, or even reverse, the Earth's rotation in a few months for any realistic mantle viscosities. A simple numerical estimation can illustrate this point. To produce a differential motion of $1.7 \mathrm{~cm} / \mathrm{yr}$ over an asthenospheric channel with a thickness of $100 \mathrm{~km}$ and a viscosity of $10^{19} \mathrm{~Pa} \mathrm{~s}$, a equatorial stress of $5 . \times 10^{4} \mathrm{~Pa} \mathrm{~s}$ must be applied. This low level stress will produce on the whole lithosphere, a net torque of $1 . \times 10^{25} \mathrm{~Pa}$ s. Such a torque will change the rotation period of the Earth whose moment of inertia is $8 \times 10^{37} \mathrm{~kg} \mathrm{~m}^{-2}$ by the totally unrealistic value of $2.5 \mathrm{~min}$ every day! Therefore, to explain the observation, we must understand how a net rotation can be induced without associated net torque.

The motions of the plates are induced by the balance of driving and resistive torques. The driving torque is related to the lateral density variations in the mantle. It is induced by the negative buoyancy of the downgoing slabs or to the positive buoyancy under the ridges. This torque can be related to the mantle circulation [Ricard and Vigny, 1989], or alternatively to the well-known boundary forces such as slab pull and ridge push [Solomon and Sleep, 1974; Forsyth and Uyeda, 1975]. The resistive torque is the consequence of the drag imposed by the moving lithosphere to the viscous asthenosphere. It is generally assumed that the drag $\tau^{L}$ obeys a simple viscous law, so that the drag force is linearly proportional to the lithospheric velocity $V^{L}$. The drag coefficient $K$ may be regionally variable. The relationship between these quantities reads

$$
\tau^{L}=K V^{L}
$$

This equation implies two assumptions. The first is rather obvious and assumes that the velocity at the surface of the mantle is equal to zero. This hypothesis could be valid if there is a strong decoupling between the lithosphere and the underlying mantle. The second is more delicate but cannot be physically sustained. It supposes that even a net torque applied to the mantle does not induce a global rotation of the Earth. This implies that the mantle is not only rigid but also is maintained fixed in space. We must thus change equation (2) into equation (3) 


$$
\tau^{L}=K\left(V^{L}-V^{M}\right),
$$

where $V^{M}$ is the mantle velocity beneath the lithosphere. If we make again the hypothesis that the mantle is rigid, we must impose that the net average of $\tau^{L}$ is zero and that $V^{M}$ is a rigid rotation. These conditions were not realized by equation (2).

By inspection of equation (3), we see that if the coupling coefficient $K$ is constant, when the net average of $\tau^{L}$ is equal to zero, the net differential rotation, which is the average of $V^{L}-V^{M}$, is also equal to zero. Only the coupling between the lateral variations of $K$ and the surface velocity can lead to a zero average of $\tau^{L}$ and a nonzero average of $V^{L}-V^{M}$. We can also see that even with variations in the coupling between lithosphere and asthenosphere, a pure rigid rotation at the surface induces a pure rotation of the whole planet without associated stresses.

Quantitatively, we can estimate the value of $K$ by considering that between the surface and the depth $H$, the Earth has a variable viscosity $\eta(r, \theta, \phi)$. In a thin shell approximation, the shear stress can be considered constant and the vertically averaged rheological law leads to

$$
V^{L}-V^{M}=H\left(\frac{1}{\eta}\right) \tau^{L}
$$

where $\langle 1 / \eta\rangle$ is the vertical average other the depth $H$ of $1 / \eta$ and is a function of latitude and longitude. In this equation, $H$ is the thickness of an outer shell which contains all the lateral viscosity variations. This thickness is supposed to be smaller than the characteristic length of the plates. By comparing equations (3) and (4) we see that we can write

$$
K=\left(H\left\langle\frac{1}{\eta}\right\rangle\right)^{-1}
$$

\section{Differential Velocity for a Rigid Mantle}

Our aim is to verify that using a realistic coupling function, equation (3) can explain the observed lithospheric rotation. Of course, this equation does not describe all the kinematics of the plates. On the real Earth, the driving forces, which are not considered here, induce a torque which cancels the one produced by the resistant stresses of equation (3).

A simple calculation can be done in a model where the rigid plates are moving on top of a rigid mantle. We have seen that the mantle velocity is described by a pure rotation $\Omega_{0}$ whereas the surface plate is described by $i$ rotation vectors $\Omega_{i}$, where $i$ is the number of plates. The requirement that the net torque must vanish leads, using equation (3), to

$$
\int K \sum_{i}\left(\Omega_{i} \times r\right) \times r \delta(i, \theta \phi) d s=\int K\left(\Omega_{0} \times r\right) \times r d s
$$

where $\delta(i, \theta \phi)$ is 0 or 1 depending whether $\theta \phi$ points to the $i^{\text {th }}$ plate or not. After expressing the double vectorial product, equation (6) reads

$$
\sum_{i} P_{i} \Omega_{i}=\left(\sum_{i} P_{i}\right) \Omega_{0}
$$

where $P_{i}$ are simple matrices formally identical to inertial matrices for a body of equivalent surface density $K_{i}=$ $K \delta(i, \theta \phi)$,

$$
P_{i}=\int K_{i}\left(\begin{array}{ccc}
-\left(y^{2}+z^{2}\right) & x y & x z \\
x y & -\left(x^{2}+z^{2}\right) & y z \\
x z & y z & -\left(x^{2}+y^{2}\right)
\end{array}\right) d s .
$$

Equation (7) is clearly independent from the reference frame as the addition of a given rotation vector $\Omega$ to all the plate rotation vectors $\Omega_{i}$, induces the same amount of rotation $\boldsymbol{\Omega}$ to the mantle. Therefore we can deduce from equation (7) the net rotation of the lithosphere $-\Omega_{0}$ when we chose for $\Omega_{i}$ the rotation poles of the plates in a no-net rotation frame.

We could have tried to find the function $K$ which should be used in equation (6) in order to exactly fit the observed rotation pole. Unfortunately, the inversion of the two-dimensional continuous function $K$ using only the observed three components of the differential velocity is highly nonunique. However, we saw that the rotation is clearly related to the Pacific plate motion, i.e., to the main oceanic plate. From seismic tomography, it also appears that continents and oceans are strongly differentiated in the top of the upper mantle. Therefore, to test our approach, we use a very simple model for the coupling function $K$. We assume that the coupling coefficient $K$ is equal to 1 under oceanic areas and $K_{c}$ under continental ones.

Figure 4 depicts the misfit deduced from equation (7), $\sqrt{\left(\Omega_{0}^{c a l}-\Omega_{0}^{o b s}\right)^{2}}$ expressed in centimeter per year as a function of $K_{c}$. When $K_{c}=1$ the differential velocity is equal to 0 and the misfit is equal to the net rotation that we deduced from NUVEL-1, $1.7 \mathrm{~cm} / \mathrm{yr}$. The misfit function shows a clear minimum for a coupling coefficient 7 times larger under continents than under oceans. In this case the observed misfit is around $0.3 \mathrm{~cm} / \mathrm{yr}$, a value which is smaller than the differences between the estimations of the observed global rotations deduced from AM1, AM1-2, and HS2-NUVEL1.

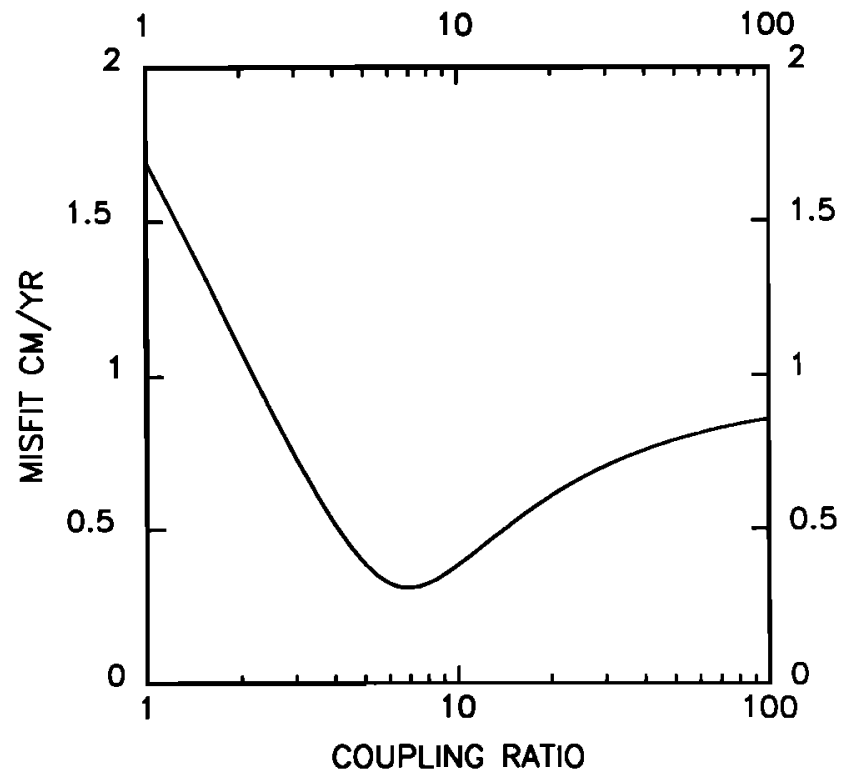

Fig. 4. Misfit between the observed and computed net rotation of the lithosphere in centimeters per year as a function or the ratio between the continental and oceanic coupling coefficients. The coupling ratio is plotted on a logarithmic scale. 
At the minimum the computed rotation is of $1.7 \mathrm{~cm} / \mathrm{yr}$ around a pole located at $93^{\circ} \mathrm{E}$ and $47^{\circ} \mathrm{S}$. The corresponding pole is plotted on Figure 2 (solid circle). Our model indicates a preferred value of around 7 for the viscosity increase between oceanic and continental regions. This number represents the ratio of the vertically averaged inverse viscosity of the two domains (equation (5)). At a given depth, the lateral viscosity variations can, of course, be larger.

The good fit realized by our simple model suggests that the real lateral viscosity variations are indeed, closely related to the ocean-continent distribution. Of course, the remaining misfit must not be interpreted as associated to a nonzero net torque applied to the mantle. It rather indicates that the coupling function is not strictly proportional to the ocean function.

\section{Differential Velocity for a Viscous MANTLE}

In order to solve the equation (3) for a more realistic viscous mantle, we use the same mathematical formulation as described by Ricard et al. [1988]. This formulation assumes that below the lithosphere, the vertical gradient of the horizontal velocity is much larger than the ratio of the surface velocity over the Earth's radius. Our Earth geometry comprises one central sphere with radial mechanical properties, and an outer shell of thickness $H$ in which the viscosity also varies with latitude $\theta$ and longitude $\phi$. In this shell the lithospheric viscosity is $\eta_{0}$ between the surface and the depth $L(\theta, \phi)$, then $\eta_{1}$ in the asthenospheric channel extending from $L(\theta, \phi)$ to $H$. The radially averaged inverse viscosity which enters equation (4) reads

$$
\left\langle\frac{1}{\eta}\right\rangle=\frac{1}{\eta_{1}}+\left(\frac{1}{\eta_{0}}-\frac{1}{\eta_{1}}\right) \frac{L}{H} .
$$

In the inner sphere, the dynamics is suitably solved by the expansion of the different quantities, such as velocities and stresses, on the basis of generalized spherical harmonics [Phinney and Burridge, 1973]. Simple relationships between the spectral components of $\tau^{L}$ and $V^{M}$ can be found [Hager and O'Connell, 1981; Ricard et al., 1984, 1988]. These relationships can be summarized as follows:

$$
\left(\tau^{L}\right)^{+}=F\left(k_{H}^{p}, k_{H}^{t}\right)\left(V^{M}\right)^{+}-\frac{H}{R} F\left(l(l+1) k_{V}^{p}, 0\right)((V))^{+}
$$

where the superscript plus means that this equation stands for the components on the basis of generalized spherical harmonics. This equation indicates that when a horizontal velocity of poloidal and toroidal components $\left(V^{M}\right)^{+}$is imposed at the surface of a viscous sphere of radius $R$, the associated stress field is obtained by applying the operator $F$, which multiplies the poloidal and toroidal velocity components of degree $l$ by $k_{H}^{p}$ and $k_{H}^{t}$. The variations of the averaged horizontal velocity in the outer layer $\langle V\rangle$ drive a vertical flow at the converging and diverging zones, which induces another poloidal stress field described by the coefficient $k_{V}^{p}$. This ensures the mass conservation of the lithosphere through the zone of subduction and ridges.

In the outer layer, the flow is described by the equation (4). Other relationships must be introduced to define the average horizontal velocity $\langle V\rangle$. It reads

$$
\langle V\rangle=C V^{L}+(1-C) V^{M}
$$

where

$$
C=\frac{1}{2}+\frac{L(L-H)}{H^{2}} \frac{\eta_{0}-\eta_{1}}{2 \eta_{0} \eta_{1}\langle 1 / \eta\rangle}
$$

This equation expresses the horizontal average velocity of a Couette flow embedded between two boundaries of velocity $V^{L}$ and $V^{M}$.

The mathematical problem requires the solution of a set of local equations (equations (3) and (11)) and spectral equations (10). The two local equations can be written in the spectral domain:

$$
\begin{gathered}
\left(V^{L}\right)^{+}-\left(V^{M}\right)^{+}=M_{1}\left(\tau^{L}\right)^{+} \\
((V))^{+}=M_{2}\left(V^{L}\right)^{+}+\left(I d-M_{2}\right)\left(V^{M}\right)^{+} .
\end{gathered}
$$

The two matrices $M_{1}$ and $M_{2}$ are computed from the expansion of $\langle(1 / \eta)$ and $C$ in spherical harmonics. They read

$$
M_{1}\left(l_{1} m_{1}, l_{3} m_{3}\right)=\alpha_{l_{1} m_{1}}^{l_{2} m_{2} I_{3} m_{3}}\langle 1 / \eta\rangle_{l_{2} m_{2}}
$$

and

$$
M_{2}\left(l_{1} m_{1}, l_{3} m_{3}\right)=\alpha_{l_{1} m_{1}}^{l_{2} m_{2} l_{3} m_{3}} C_{l_{2} m_{2}}
$$

The coefficients $\alpha_{l_{1} m_{1}}^{l_{2} m_{2} l_{3} m_{3}}$ are computed using Wigner-3j symbols [Edmonds, 1960]

$$
\begin{aligned}
\alpha_{l_{1} m_{1}}^{l_{2} m_{2} l_{3} m_{3}}=(-1)^{l_{1}+m_{1}} & \sqrt{\frac{\left(2 l_{1}+1\right)\left(2 l_{2}+1\right)\left(2 l_{3}+1\right)}{4 \pi}} \\
& \times\left(\begin{array}{ccc}
l_{1} & l_{2} & l_{3} \\
-1 & 0 & 1
\end{array}\right)\left(\begin{array}{ccc}
l_{1} & l_{2} & l_{3} \\
-m_{1} m_{2} m_{3}
\end{array}\right)
\end{aligned}
$$

The $\alpha_{l_{1} m_{1}}^{l_{2} m_{2} l_{3} m_{3}}$ coefficients vanish unless $m_{2}=m_{1}+m_{3}$, $\left|m_{2}\right| \leq l_{2}$, and $\left|l_{1}-l_{3}\right| \leq l_{2} \leq l_{1}+l_{3}$.

Using equations (10), (13), and (14), the problem can be solved; when $V^{L}$ is the plate velocity in a no-net rotation frame, the toroidal coefficients of degree 1 of $V^{M}$ are directly proportional to the lithospheric rotation.

To avoid edge effects in the description of the inverse viscosity variations in spherical harmonics, we have chosen to take the smooth function $L(\theta, \phi)$ whose normalized lateral variations are depicted on Figure 5 . This function is a filtered version of the ocean function and only contains harmonics of degrees smaller or equal to 10 . The grey areas over continents correspond to a thick lithosphere, whereas the oceans are underlaid by a thinner lithosphere. We chose the amplitude and average value of the function $\mathrm{L}$ in order to have a lithosphere with a thickness going from 0 to $H=100$ $\mathrm{km}$. From equation (9), the lateral variations of the inverse viscosity are going exactly from the lowest value $1 / \eta_{0}$ to the highest value $1 / \eta_{1}$.

In our formulation, only the average inverse of viscosity enters. The lithospheric thickness function that we have used is only an easy way to scale our viscosity variations; of course, the real lithosphere cannot reach a zero thickness. Other heuristic models, such as a model with uniform viscosity underlain by an asthenosphere with lateral viscosity variations, could have lead to the same inverse viscosity function.

Beneath the outer shell with its lateral viscosity variations, we consider a mantle made up of two layers, an upper part with viscosity $\eta_{u}$ and a lower part with viscosity $\eta_{l}$ which extends from the depth $D$ to the core-mantle bound- 


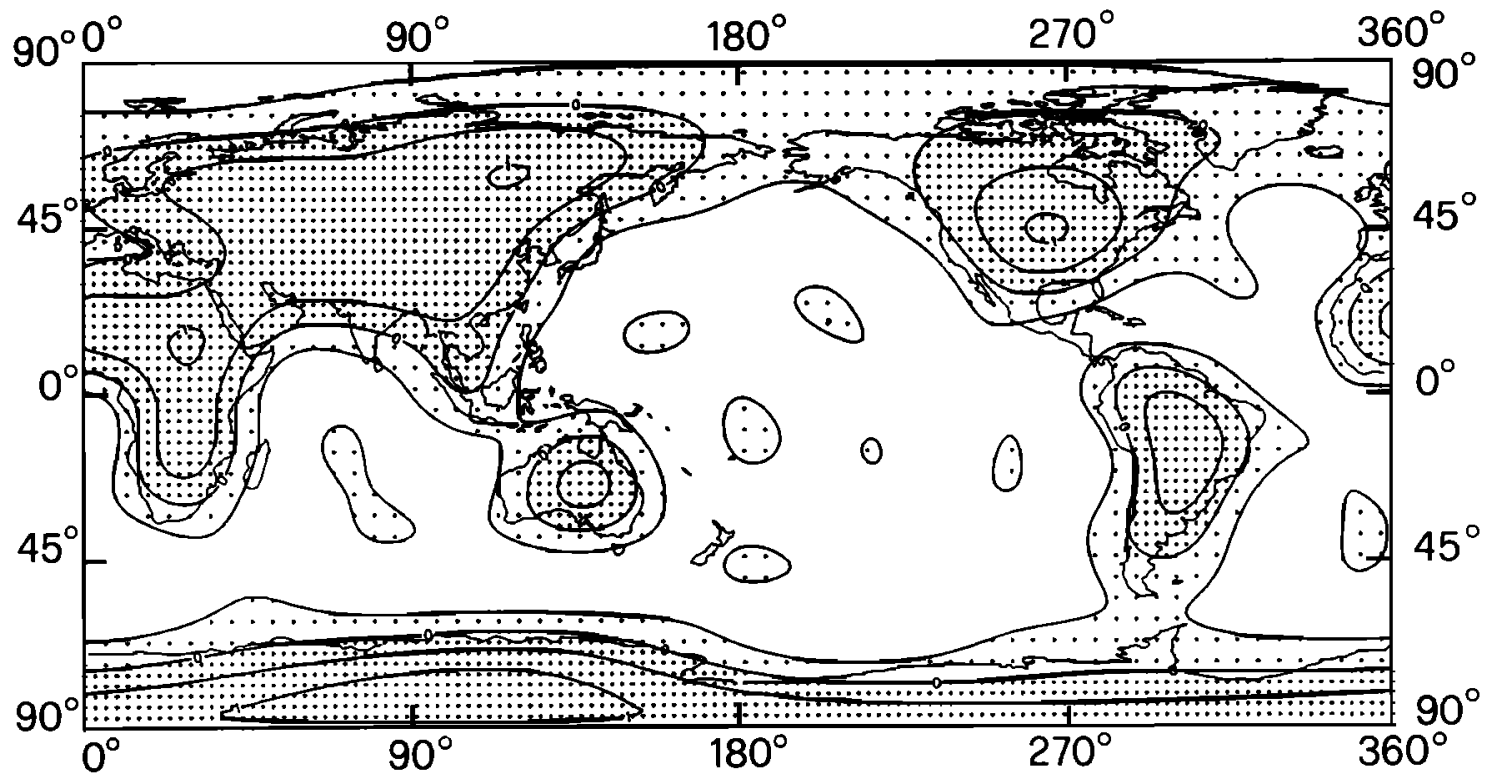

Fig. 5. Lateral variations of the average inverse viscosity in our outer shell. The grey continents correspond to a high viscosity, whereas the nonshaded oceans are underlaid by a lower viscosity. This normalized function is a filtered version of the ocean-continent distribution and only contains spherical harmonics of degrees smaller than 10 . The local maxima in the oceans are due to Gibbs effects related to the spectral truncation. The inverse averaged viscosity is exactly $1 / \eta_{0}$ at its minimum and $1 / \eta_{1}$ at its maximum.

ary. We ran the computation taking into account all the coupling coefficients up to a degree $l_{\max }$ going from $l_{\max }=10$ to $l_{\max }=15$. We verified that for $l_{\max }=15$ an asymptotic value was attained; the coupling of lateral viscosity variations of degrees larger than 15 with velocity described by vector harmonics of degree larger than 15 will not significantly change our estimation of the lithospheric differential velocity.

Figure 6 depicts by means of isolines the misfit between the observed and modelled differential rotation as a function of the ratios $\eta_{0} / \eta_{1}$ and $\eta_{0} / \eta_{u}$ for different values of $D$ and $\eta_{l} / \eta_{0}$. Figures $6 a$ and $6 b$ are for $\eta_{l}=\eta_{0}$; in Figures $6 c$ and $6 d$, the viscosity in the lower part of the mantle has been increased by a factor 10 . In Figures $6 a$ and $6 c$, the radial viscosity transition within the mantle is at the upper-lower mantle boundary $(D=650 \mathrm{~km})$; in Figures $6 b$ and $6 d$ the viscosity increase lies below a thin low-viscosity channel ( $D$ $=250 \mathrm{~km}$ ).

In all graphs, the right lower part with the darkest shading represents a zone where the misfit is larger than $1.7 \mathrm{~cm} / \mathrm{yr}$ and therefore larger than the signal itself. The smaller misfits are attained in the zone without shading. The best solutions can explain more than $70 \%$ of the observation (a misfit of $0.5 \mathrm{~cm} / \mathrm{yr}$ ). This satisfactory fit advocates for a strong correlation between the lateral viscosity variations of the real Earth and the ocean-continent distribution. The lateral viscosity variations required are always larger than what has been found in the simpler model with a rigid mantle. However, if a viscosity contrast by a factor of 70 is required for a uniform mantle (Figures $6 a$ and $6 b$ ), an increase of the lower mantle viscosity (Figure $6 c$ ) reduces this contrast to a factor 30. These lateral variations are further reduced to a factor around 20 if we impose a viscosity increase just below an asthenospheric channel (Figure $6 d$ ). For a given upper mantle viscosity, an increase in the lower mantle viscosity leads to a decrease in the necessary lateral viscosity variations: our model tends to the asymptotic limit we found for a rigid mantle. For a given lower mantle viscosity, a decrease in the upper mantle viscosity leads to an increase of the lateral viscosity variations: an inviscid asthenosphere would lead to a zero differential velocity.

\section{CONCLUSIONS}

The existence of a global westward rotation of the lithosphere with respect to the hotspots is strongly suggested by data. This rotation is rather independant of the chosen hotspot traces and of the absolute velocities chosen for the Pacific volcanoes. This rotation is a real one and is not an artifact of the choice of the reference frame in which plate motions are defined. As a consequence, an anchoring effect of the subducted slabs in the mantle which is eastward migrating is expected. This mechanism could explain the observed larger dips of the west dipping subductions which contrast the mantle flow and the opening of the back arc basins.

This net rotation is forbidden by the models where the Earth's properties are radially stratified. We show that a net rotation naturally appears in the models where lateral viscosity variations are allowed, the amplitude of this toroidal field being directly related to the amount of lateral variations. A similar conclusion has been drawn by $O$ 'Connell et al. [1991]. The observed rotation with a pole in the southern part of the Indian Ocean and an amplitude of $1.7 \mathrm{~cm} / \mathrm{yr}$ can be simply explained by a viscosity contrast between suboceanic and subcontinental mantle. Such a viscosity contrast agrees well with seismic tomography of the upper mantle, that systematically indicates the existence of fast roots beneath continental areas, in distinct contrast with the slow oceanic regions. If these seismic velocity anomalies are thermal or compositional in origin, we must expect lateral viscosity variations of 1 or 2 orders of magnitude. Furthermore, these lateral variations are also consistent with heat flow data based on the interpretation of seismic tomography in terms of thermal and compositional anomalies [Yan et 

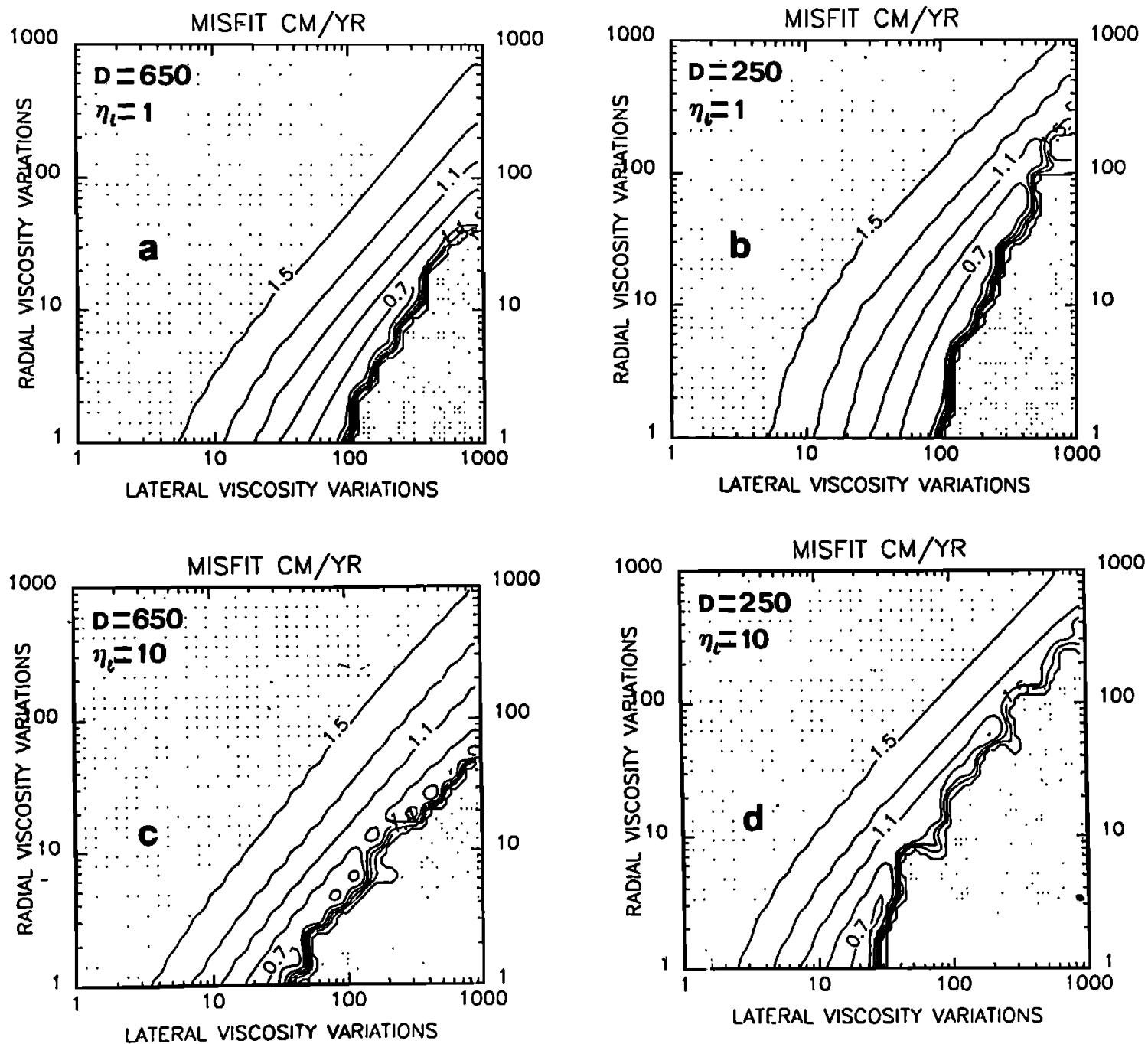

Fig. 6. Misfits depicted by means of isolines, between the observed and computed net rotation of the lithosphere in centimeters per year. The horizontal axis depicts the ratio between subcontinental and suboceanic viscosity $\eta_{0} / \eta_{1}$. The vertical axis depicts the ratio between sub-continental viscosity and the viscosity of the top part of the upper mantle $\eta_{0} / \eta_{l}$. Below the outer shell, the mantle viscosity varies radially and presents a viscosity jump at the depth $D$. This depth is $650 \mathrm{~km}$ for Figures $6 a$ and $6 c$, and $250 \mathrm{~km}$ for Figures $6 b$ and $6 d$. The viscosity of the lower part of the mantle is 1 in Figures $6 a$ and $6 b$, and 10 in Figures $6 c$ and $6 d$.

al., 1989]. A substantial decrease of the upper mantle viscosity beneath the oceanic lithosphere is also strongly supported by the analyses of the Holocene sea level changes in oceanic island sites located in the far field with respect to the Pleistocenic Arctic and Antarctic ice sheets [Nakada and Lambeck, 1989].

A trade-off exists between lateral and radial viscosity variations. An increase in the lower mantle viscosity confines the return flow more efficiently in the upper mantle and decreases the amplitudes of the requested lateral viscosity variations. Our calculations are consistent with lateral viscosity variations ranging from one to two orders of magnitude between continental and oceanic regions, for any realistic radial viscosity profile in the mantle.

It should be emphasized that in the present modeling, we do not account for lateral viscosity variations below a given depth, assuming that below this depth the lateral viscosity variations are of lesser amplitudes. This implies that we do not have any differential rotation within the underlying mantle. The lithospheric rotation that we computed is therefore a net rotation of the lithosphere with respect to the whole mantle, independently from the location of the hotspots sources.

Acknowledgments. We are grateful to G. V. Dal Piaz for useful discussions. One of us (Y. Ricard) was a fellow of ESA (European Space Agency) at the University of Bologna (Italy). This work has been partly supported by the INSU-DBT (Dymamique et Bilan de la Terre) program (contribution 270), and by the ASI (Agenzia Spaziale Italiana).

\section{REFERENCES}

Bostrom, R. C., Westward displacement of the lithosphere, $\mathrm{Na}$ ture, 294, 536-538, 1971.

Burke, K., and J. T. Wilson, Is the African plate stationary?, Nature, 239, 387-390, 1972.

Chopin, C., Coesite and pure Pyrope in high grade blueschists of the Western Alps: A first record and some consequences, Contrib. Mineral. Petrol., 86, 107-118, 1984.

DeMets, C., R. G. Gordon, D. F. Argus, and S. Stein, Current plate motions, Geophys. J. Int., 101, 425-478, 1990.

Doglioni, C., The global tectonic pattern, J. Geodyn., 12, 21-38, 1990.

Edmonds, A. R., Angular Momentum in Quantum Mechanics, Princeton University Press, Princeton, N. J., 1960. 
Forsyth, D., and S. Uyeda, On the relative importance of driving forces of plate motion, Geophys. J. R. Astron. Soc., 43, 163 $200,1975$.

Garfunkel Z., C. A. Anderson, and G. Schubert, Mantle circulation and the lateral migration of subducted slabs, J. Geophys. Res., 91, 7205-7223, 1986.

Gripp, A. E., and R. G. Gordon, Current plate velocities relative to the hotspots incorporating the Nuvel-1 global plate motion model, Geophys. Res. Lett., 17, 1109-1112, 1990.

Hager, B. H., and R. J. O'Connell, A simple global model of plate dynamics and mantle convection, J. Geophys. Res., 86 4843-4867, 1981.

Jordan, T. H., Some comments on tidal drag as a mechanism for driving plate motions, J. Geophys. Res, 79, 2141-2142, 1974.

Knopoff, L., and A. Leeds, Lithospheric momenta and the deceleration of the Earth, Nature, 297, 93-95, 1972.

Le Pichon, X., Sea floor spreading and continental drift, J. Geophys. Res., 79, 3661-3697, 1968.

Lliboutry, L., Plate movement relative to rigid lower mantle, $\mathrm{Na}$ ture, 250, 298-300, 1974.

Minster, J. B., and T. H. Jordan, Present-day plate motion, $J$. Geophys. Res., 89, 5331-5354, 1978.

Minster, J. B., T. H. Jordan, P. Molnar and E. Haines, Numerical modelling of instantaneous plate tectonics, Geophys. J. $R$. Astron. Soc., 36, 541-576, 1974.

Moore, G. W., Westward tidal lag as the driving force of plate tectonics, Geology, 1, 99,-101, 1973.

Morgan, W. J., Convection plumes in the lower mantle, Nature, 290, 42-43, 1971.

Morgan, W. J., Deep mantle convection plumes and plate motions, Am. Assoc. Pet. Geol. Bull., 56, 203-213, 1972.

Nakada, M., and K. Lambeck, Late Pleistocene and Holocene sea-level change in the Australian region and mantle rheology, Geophys. J. Int., 96, 497-517, 1989.

Nelson, T. H., and P.B. Temple, Mainstream mantle convection: A geologic analysis of plate motion, Am. Assoc. Pet. Geol. Bull., 56, 226-246, 1972.

O'Connell, R. J., C. W. Gable, and B. H. Hager, Toroidal-poloidal partitioning of lithospheric plate motions, in Glacial Isostasy, Sea Level and Mantle Rheology, edited by R. Sabadini and K. Lambeck, Kluwer Academic Publishers, Dordrecht, in press, 1991.
Phinney, R. A., and R. Burridge, Representation of the elasticgravitational excitation of the spherical Earth model by generalized spherical harmonics, Geophys. J. R. Astron. Soc., $\gamma_{4}$, 451-487, 1973.

Ricard, Y., and C. Vigny, Mantle dynamics with induced plate tectonics, J. Geophys. Res., 94, 17,543-17,559, 1989.

Ricard, Y., L. Fleitout, and C. Froidevaux, geoid heights and lithospheric stresses for a dynamical Earth, Ann. Geophys., 2, 267-286, 1984.

Ricard, Y., C. Froidevaux, and L. Fleitout, Global plate motion and the geoid, a physical model, Geophys. J., 93, 477-484, 1988.

Sabadini, R., C. Doglioni, and D. A. Yuen, Eustatic sea level fluctuations induced by polar wander, Nature, 345, 708-710, 1990.

Solomon, S. C., and N. H. Sleep, Some simple physical models for absolute plate motions, J. Geophys. Res., 79, 2557-2567, 1974.

Uyeda, S., and $H$. Kanamori, Back arc opening and the mode of subduction, J. Geophys. Res, 84, 1049-1061, 1979.

Wang, X., J. L. Liou, and H. K. Mao, Coesite-bearing eclogite from the Dabie Mountains in Central China, Geology, 17, 1085$1088,1989$.

Wilson, J. T., Evidence from ocean islands suggesting movement in the Earth, Philos. Trans. R. Soc. London, Ser. A, 285, 145-165, 1965.

Yan, B., E. K. Graham, and K. P. Furlong, Lateral variations in upper mantle thermal structure inferred from three dimensional seismic inversion models, Geophys. Res. Lett., 16, 449-452, 1989.

C. Doglioni, Dipartimento di Scienze Geologiche, Università di Ferrara, Corso Ercole I D'Este 32, 44100 Ferrara, Italy. Y. Ricard, Département de Géologie, Ecole Normale Supérieure, 24, rue Lhomond, 75231 Paris Cedex 05, France.

R. Sabadini, Dipartimento di Fisica, Settore di Geofisica, Università di Bologna, Viale Berti Pichst 8, 40127 Bologna, Italy.

(Received September 6, 1990; revised January 7,1991 , accepted January 14, 1990.) 